\title{
Eye injuries in organised sport in a rural area
}

\author{
SIMON KELLY AND JOHN NOLAN \\ From the Department of Ophthalmology, Regional Hospital, Galway, Ireland
}

SUMMARY Eye injuries in sport are a continuing preventable problem. An investigation into sport injuries in rural Ireland shows hurling to be the most dangerous pastime, and this is compared and contrasted with other local games. Forty-five consecutive injuries sustained in organised sport requiring admission to hospital over a 4-year period were studied. $40 \%$ were due to hurling. Over three-quarters of the 45 patients recovered $6 / 6$ vision or better. The costs to the community of such eye injuries are discussed.

With increasing leisure time and the encouragement of widespread exercise programmes by governments, educators, and the medical profession there has been an increase in eye injuries in various sports. ${ }^{1-5}$

This survey deals with the causes and types of eye injuries in organised sport in the West of Ireland. Hurling and Gaelic football are the national sports and enjoy a large, active participation. It is no surprise to find that these contact sports are common causes of eye injury in the region. Hurling in particular seems likely to cause eye injuries. It is a fast, 15 man a-side, contact field game. It is played with a solid ball and wooden stick, or hurley. The ball is $75 \mathrm{~mm}$ in diameter, which fits snugly into the orbital opening, and it travels at a velocity of 30 metres per second with a kinetic energy of 50 joules. The hurley stick can be raised to any height above the head in play. The ball can be struck with either side of the stick at any level. No eye protection is worn, and only a minority of players wear helmets - a relatively novel and non-compulsory introduction. ${ }^{6}$

The game of hurling dates back to at least the times of the Tailteann Games (1829 BC), but in contrast to

Correspondence to Dr S. Kelly, Western Ophthalmic Hospital, Marylebone Road, London, NW1 5 YE.

Table 1 Age distribution of injured patients

\begin{tabular}{ccr}
\hline Age group & No. injured & $\%$ \\
\hline $0-9$ & 2 & $4 \cdot 4$ \\
$10-19$ & 11 & $24 \cdot 4$ \\
$20-29$ & 20 & $44 \cdot 4$ \\
$30-39$ & 7 & $15 \cdot 6$ \\
$40-49$ & 3 & $6 \cdot 7$ \\
$49+$ & 2 & $4 \cdot 4$ \\
Total & 45 & \\
\hline
\end{tabular}

Mean age 25 years. the youthful sports of squash (AD 1817) and ice hockey (16th century), ${ }^{7}$ which are also noteworthy causes of eye injuries, it has attracted little attention from ophthalmologists. Two papers from casualty departments have dealt with general and facial injuries in hurlers. ${ }^{89}$ The only available ophthalmological report described 10 cases of eye injury in hurling, in only 2 of which did the patients recover normal visual acuity. ${ }^{10}$

\section{Patients and methods}

Forty-five consecutive patients (45 eyes) who sustained eye injuries in organised sport and required admission to hospital between 1 January 1979 and 31 December 1982 were studied. Forty-four patients were players, one was a referee. The final visual acuity for 40 patients was ascertained. Five cases were lost to follow-up.

\section{Results}

Age. There were $37(82.2 \%)$ male and $8(17.7 \%)$ female patients. Their ages are shown in Table 1 and averaged 25 years.

Twenty-seven patients were in full-time employment. Fourteen were full-time students. Three were full-time housewives. One patient was unemployed.

Aetiology. The sport concerned in each case is shown in Table 2. Hurling was the single biggest cause of the injuries $(40 \%)$. Football of various varieties accounted for 13 cases $(28.9 \%)$. The racquet sports squash and badminton were responsible for 9 cases $(20 \%)$. Golf provided 2 cases $(4 \cdot 4 \%)$. Handball, table tennis, and fishing provided 1 case each $(2.2 \%)$ and are grouped together as 'others' on Table 2.

The exact cause of the injury was known to 43 
Table 2 Cause of eye injury, percentage figures in brackets

\begin{tabular}{|c|c|c|c|c|c|}
\hline Sport & $\begin{array}{l}\text { Ball, } \\
\text { shuttlecock }\end{array}$ & $\begin{array}{l}\text { Stick, } \\
\text { racquet, etc. }\end{array}$ & $\begin{array}{l}\text { Direct } \\
\text { contact }\end{array}$ & $\begin{array}{l}\text { Not } \\
\text { known }\end{array}$ & Total \\
\hline Hurling & $11(61)$ & $5(45)$ & 0 & $2(11)$ & $18(40)$ \\
\hline Football, Gaelic & $2(33)$ & 0 & $4(66)$ & 0 & $6(13 \cdot 3)$ \\
\hline Squash & $5(100)$ & 0 & 0 & 0 & $5(11 \cdot 1)$ \\
\hline Soccer & $3(75)$ & 0 & $1(25)$ & 0 & $4(8.9)$ \\
\hline Badminton & $4(100)$ & 0 & 0 & 0 & $4 \quad(8.9)$ \\
\hline Rugby & $1(33)$ & 0 & $2(67)$ & 0 & $3(6 \cdot 7)$ \\
\hline Golf & $2(100)$ & 0 & 0 & 0 & $2(4.4)$ \\
\hline Others & $2(67)$ & $1(33)$ & 0 & 0 & $3(6 \cdot 7)$ \\
\hline Total & 30 (67) & $6(13)$ & $7(16)$ & $2(4)$ & 45 \\
\hline
\end{tabular}

patients. Two others, both injured in hurling matches, could not recall how or by whom they were struck. Over all the ball accounted for two-thirds of all injuries, 30 out of 45 cases. In the games of squash, badminton, golf, table tennis and handball it was responsible for $100 \%$ of injuries; $61 \%$ of hurling injuries were due to the ball. In the 3 varieties of football the ball injuries- 6 cases $(46 \%)$-were outnumbered by injuries due to direct bodily contact such as blows, punches, and kicks, which accounted for 7 cases $(54 \%)$.

Ocular damage and treatment. This is shown in Table 3. No player received an injury to more than one eye. No player returned with a second eye injury during the 4-year period. The 45 patients received 113 different injuries to the eye. The commonest of these, 34 cases ( $30 \%$ of all injuries), were soft-tissue injuries to the eyelids and conjunctiva. Hyphaema occurred in 30 cases $(26.5 \%)$. Three patients had a second bleed while in hospital. All hyphaemas were managed conservatively. An uncomplicated iritis occurred in 14 cases $(12 \cdot 4 \%)$. Transient vitreous haemorrhage and transient episodes of raised intraocular pressure occurred in 6 cases $(5.3 \%)$. Retinal injuries were present in 6 patients $(5 \cdot 3 \%)$, of whom three developed retinal detachments, 2 traumatic maculopathies, and 1 a persistent field defect following a choroidal rupture. The 45 patients spent 185 days in hospital and required 17 surgical procedures. Eight of these were primary lid wound debridement and suturing under local anaesthesia. Nine cases required general anaesthesia. Of these, 3 were repair of retinal detachments, 2 canniculoplasties, 1 extracapsular cataract extraction, 1 reduction of orbital fracture, 1 repair of severe eyelid lacerations, and 1 case required burr holes. No patient was wearing a protective device for the eye when injured. Three patients were wearing glass corrective lenses in street-wear frames; all of these were shattered, but only one sustained a corneal laceration, and this was superficial.

Table 3 Distribution of eye injuries in 45 patients by aetiology and type of injury

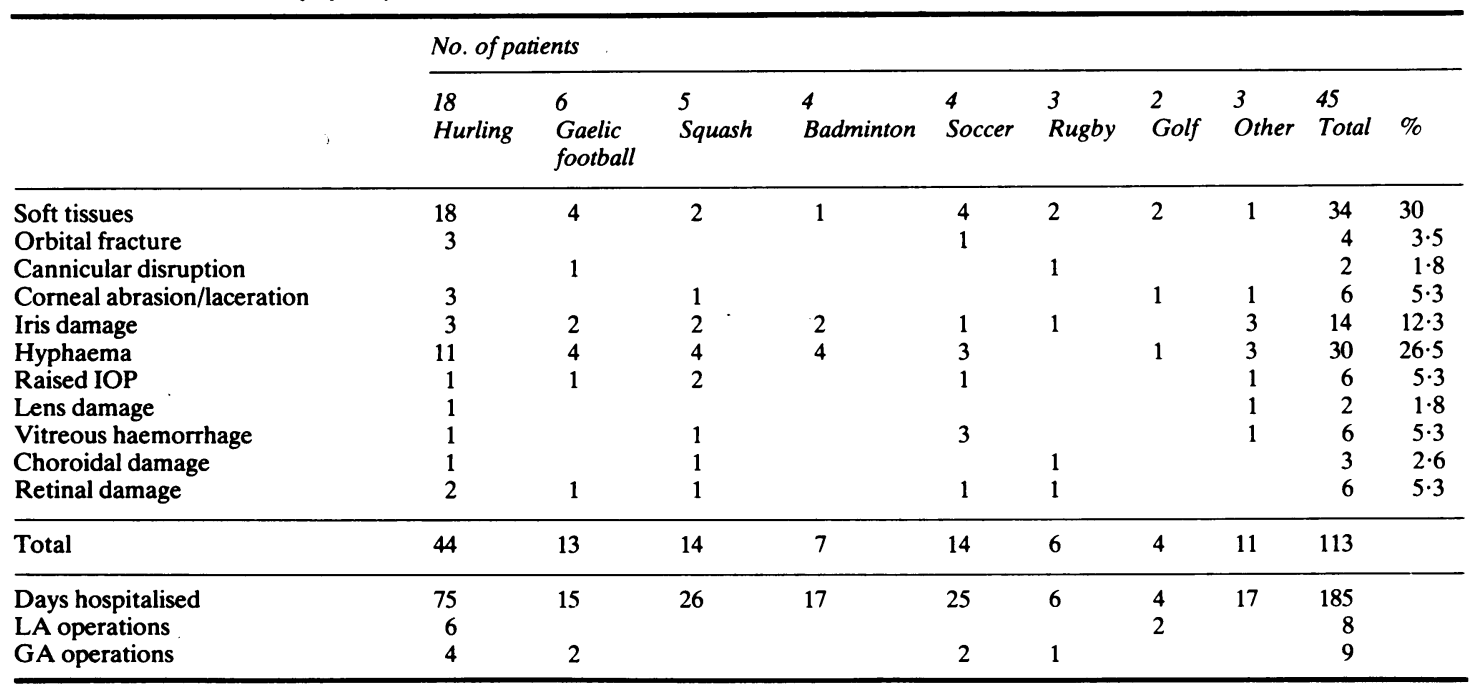


Table 4 Final corrected visual acuity in 40 eyes*

\begin{tabular}{lcc}
\hline Final visual acuity & No. eyes injured & $\%$ \\
\hline $6 / 6$ or better & 31 & $77 \cdot 5$ \\
$6 / 9-6 / 12$ & 6 & 15 \\
$6 / 18-6 / 36$ (includes 2 amblyopic & & \\
$\quad$ eyes) & 2 & 5 \\
$6 / 60$ or worse & 1 & $2 \cdot 5$ \\
No perception of light & 0 & 0 \\
Enucleation & 0 & 0 \\
Total & 40 & 100 \\
\hline
\end{tabular}

*The final visual acuity was unknown in 5 cases.

Final visual acuity (Table 4). Of the 40 patients available for follow-up $31(77 \cdot 5 \%)$ recovered $6 / 6$ vision or better. Only one $(2.5 \%)$ had a final visual acuity of less than $6 / 60$; this was due to a hurling ball maculopathy.

\section{Discussion}

Sports injuries have been described as 'an unthwarted epidemic' and have been estimated to be 90\% preventable by the United States National Society to Prevent Blindness. ${ }^{11}$ This study suggests a need for preventive measures in order to protect the eyes, at least in hurley players. The 2 previous reports on eye and head injuries in hurling have both advised eye protection. ${ }^{810}$ The present study confirms that hurling is the commonest cause of serious sporting eye injury in the West of Ireland and that the lack of eye protection in this sport is a cause for concern. While it is encouraging that the majority of patients regained $6 / 6$ vision or better, there is no doubt that all patients suffered some disability which could perhaps have been avoided, or lessened, had a protective device been worn. In addition, since $86.6 \%$ of the patients were 35 years old or under, those who did suffer permanent disability will carry this with them for many years to come. The one patient whose final visual acuity was less than $6 / 60$ due to maculopathy following a hurling injury was aged 15 years.

Those injured required on average $4 \cdot 1$ days in hospital, and every fifth patient required a general anaesthetic. Only one of the 45 injured people was unemployed at the time. The $\mathbf{4 4}$ others all lost some time off their usual work or studies while inpatients, convalescing, and receiving follow-up treatment and review. These costs and the loss of worker productivity are in the end borne by the community, either through taxation or insurance premiums. Since the resources available to health care are limited, the investment in devices which might reduce the cost of eye injury disability makes sound economic sense and indeed is value for money to the individual player. Vinger ${ }^{11}$ estimated a reduction of 70000 eye and facial injuries in ice hockey in the USA in 1979 at a saving of 10 million US dollars with the widespread use of face masks. Despite the expense and suffering of eye injury recent reports from Britain $^{1213}$ and New Zealand ${ }^{14}$ indicate that squash players remain unconvinced of the need for eye protection, for it is rarely worn and apparently unfashionable.

The view may be taken that there is an 'assumption of risk'-volenti non fit injuria-understood in participating in sport and that those who do so play at their own peril. While this is valid, and is part of the excitement in participating in contact sports, this study underlines the cost to the community of such injuries. Suitable eye protection has been shown to reduce the incidence of injuries in ice hockey in Canada. ${ }^{15}$ The type recommended is a full-face wire mesh attached to a helmet which provides maximum protection to the eye and face with minimal reduction in peripheral vision. Getting players to wear such a protection is another matter. It is hoped to demonstrate a similar reduction in eye injuries in hurley players wearing protective gear in the future.

We thank the Medical Records Section, Regional Hospital, Galway, Ireland, and Bride Brady, Fourth Floor Typing Pool, Regional Hospital, Galway, Ireland.

\section{References}

1 Ingram DV, Lewkonia I. Ocular hazards of playing squash rackets. Br J Ophthalmol 1973; 57: 434-8.

2 Easterbrook M. Eye injuries in racquet sports: a preventable disease. Can Med Assoc J 1978; 118: 298-305.

3 Pashby TJ, Pashby RC, Chisholm LDJ. Eye injuries in Canadian hockey. Can Med Assoc J 1975; 113: 663-6.

4 Chandran S. Ocular hazards of playing badminton. $\mathrm{Br} \mathrm{J}$ Ophthalmol 1974; 58: 757-60.

5 Millar GT. Golfing eye injuries. Am J Ophthalmol 1967: 64: 741-2.

6 The Commission of the Gaelic Athletics Association. Gaelic Athletic Association, 1971.

7 McWhirter N, Ed. Guinness book of records. 29th ed. London: Guiness Superlatives. 1983.

8 Flanagan X, Doyle J. Injuries in hurling and camogie. J Irish Med Assoc 1979; 72: 443-7.

9 O'Donoghue GM, Condon KC. Facial injuries in hurlers. J Irish Med Assoc 1979; 72: 448-9.

10 McAuliffe CD, Cleary PE. Eye injuries due to hurling. $J$ Irish Med Assoc 1982; 75: 289-90.

11 Vinger PF. Sports related eye injury, a preventable problem. Surv Ophthalmol 1980; 25: 47-51.

12 Barrell GV, Cooper PJ, Elkington AR, MacFadyen JM, Powell RG, Tormey P. Squash ball to eye ball: the likelihood of squash players incurring an eye injury. $\mathrm{Br}$ Med $\mathrm{J}$ 1981; 283: 893-5.

13 Fishlock T. Squash: fast, fashionable and risky. The Times 22 November 1979.

14 Clement RS, Fairhurst SM. Head injuries from squash: a prospective study. NZ Med J 1980; 92: 1-3.

15 Pashby TJ. Eye injuries in Canadian ice hockey, Phase II. Can Med Assoc J 1977; 117: 671-8. 